\title{
Assessment of Energy Conservation in Egypt's Electric System
}

\author{
Eng.Azhar El Saeed Awad Abou Ghoniem \\ Engineer at Alexandria Electricity Distribution Company \\ Address 9 Sidi El Metwally Street, Attareen, Alexandria, Egypt \\ mimi.az88@yahoo.com
}

\begin{abstract}
This paper proposes a simple carrierbased PWM (CBPWM) technique to control the threeto five-phase Direct Matrix Converter $(3 \times 5 \mathrm{DMC})$. The proposed technique uses the indirect modulation approach to control the $3 \times 5$ DMC such as a threephase bidirectional rectifier followed by five-phase voltage source inverter (VSI). Based on this approach, it is possible to synthesize the desired five-phase output voltages with sinusoidal three-phase input currents and unity input power factor. A CBPWM method is suggested for each stage independently including both linear and overmodulation operating modes. By the proposed technique, in both operating modes, the maximum possible overall Voltage Transfer Ratio (VTR) is achieved. Moreover, this technique allows the input power factor to be controlled by controlling the input current displacement angle. The feasibility of the proposed technique has been verified by a series of simulation and experimental results based on Matlab/Simulink and dSPACE-DS1104 platform. The results show that a sinusoidal output and input waveforms can be achieved with a maximum possible VTR in the linear region. However, in the overmodulation region, a maximum possible VTR is achieved at the cost of some distortion of output and input waveforms. Therefore, this technique can be used for the application where a higher VTR is essential.
\end{abstract}

\section{INTRODUCTION}

In the last few years Egyptian electrical system has been encountered by many challenges for instance shortage of primary source of energy which needed for generating electricity from power plants, continues increase in load demand, high value of peak load, great sum of energy subsides and high cost of investments for production, transmission and distribution of power.
Egypt 's electrical system is characterized by fuel fired electric generating power plants. Thermal electrical power plants combined of thermal, gas and combined cycle power stations have the major share of production which represents approximately $89 \%$ of electric power generation. Hydroelectric power is $9 \%$, in addition to $2 \%$ for renewable and zero nuclear power plant is included. The major contribution of fuel fired power plants is distinguished highly. Fossil fuel is the corner stone of the electric production system, green renewable energies solar and wind is very limited with no other renewable. Diversity of primary sources isn't wide. This splitting up situation confirms that thermal electric power generation represents the dominant part of the nation electric system. Although there are many considerations against consequences of burning fossil fuel upon the environment due to emission of harmful gasses, fuel fired power plants have several advantages of relatively rational cost of installations, reasonable cost of generating energy per $\mathrm{KWH}$, simple operation \& maintenance conditions and long life time. Fig (1) illustrates share of electrical power plants in Egypt's electric system EES-2014.

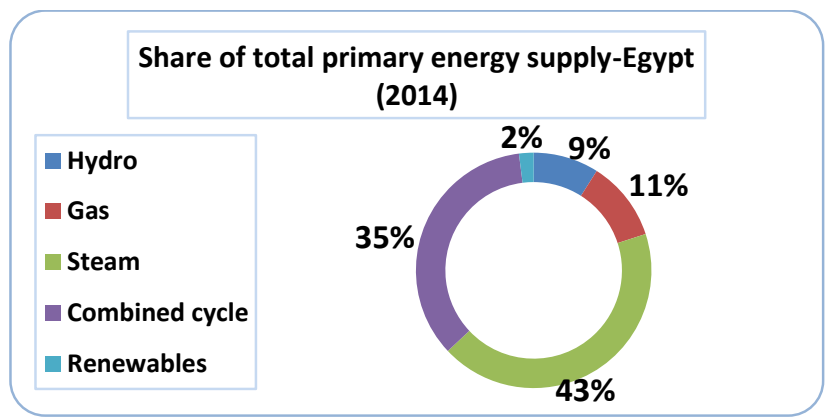

Fig .1. Egypt`s electric generation by type

Egypt's electric system has ratios of primary electric generation by type very close to that of worldwide electric system. It means thermal power plants are the dominants (global generation: $88 \%$ thermal, $1-3$ green renewable). Fig (2) shows prime electric generation by type in universal electric system (2010). 
World wide prime electric generation by type (2010)

$\square$ OIL

nATURAL GAS

- COAL

E NUCTEAR

WYDRO

RENEWABLES

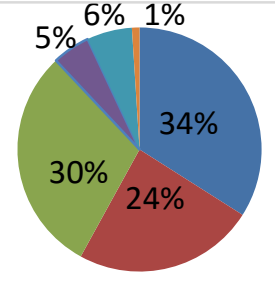

Fig .2. illustrates share of electric generation in worldwide electric power system

\section{BACK GROUND}

Primary sources of energy for Electricity generation in Egypt are basically oil and natural gas. Their production and consumption pass through three phases; first, from mid 70'S till mid 90s' increase in production was greater than consumption. Second, Oil production declined simultaneously with increase in consumption in local market till year 2005. Natural gas was substituted for oil in electricity generation. At fine, oil and natural gas productions were reduced dramatically with high increase in local consumption. A big gap between (oil \& natural gas) production and consumption is created and it has been continued till now. Therefore, electricity generation is certainly affected by deficiency of fuel [1] Fig (3) shows oil productions and consumptions during last four decades in Egypt.

Source: $\$ peak oil production

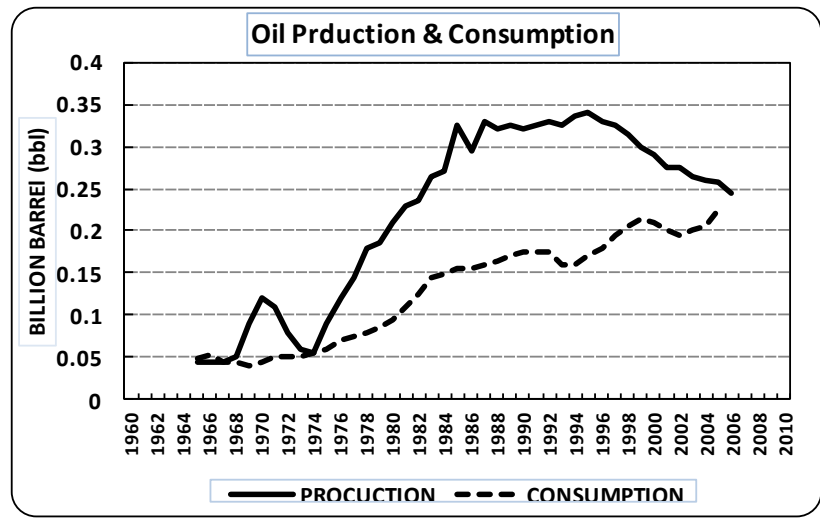

Fig .3. oil productions and consumptions in last four decades in Egypt

Assured remaining reserves for oil \& natural gas in Egypt are very limited and they decrease annually in regular bases as shown in fig (4). I n year 2030 Oil and N.G will decay almost to one third of their reserves; at then no consumption of Oil \& N.G will be admitted [5].

Source: http:// www.iea.org/statist/index.htm

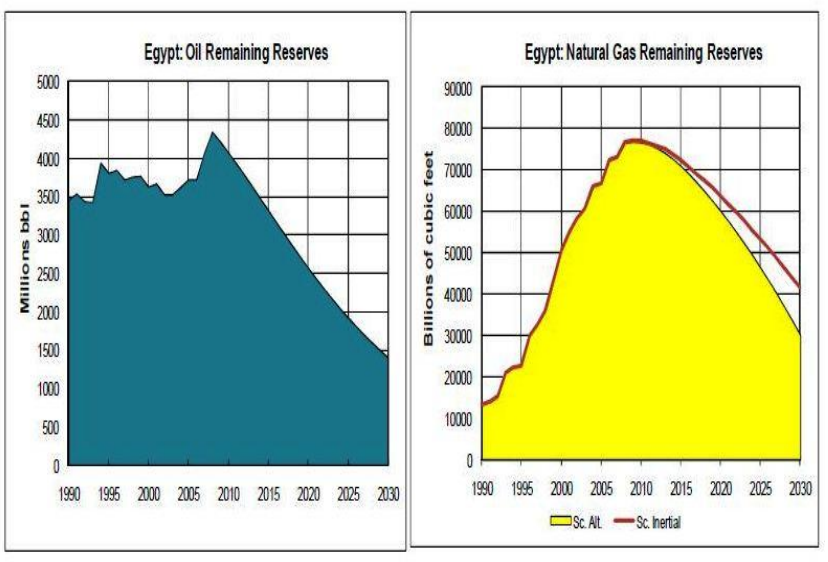

Fig .4. Remaining reserves for oil \& natural gas in Egypt

\section{EGYPT'S ELECTRIC SYSTEM CHALLENGES}

- Declining of oil \& gas productions simultaneously with raise in consumptions.

- increase in electric load demand by about $4.5 \%$ annually

- High daily peak power demand (worsen the system overall efficiency and increases energy price.

- Significant technical and un technical losses.

- Limited contribution and utilization of renewable energies.

- Lack of finance resources in energy sectors and huge budget of subsides for fuel and electricity.

- Maintenances along the network are somehow lower than recommended.

- Weakness of energy saving policies and programs in different activities.

\section{MAJOR PILLARS FOR SOLUTION}

A new energy policy for solution of Egypt's' electric system difficulties has been put into actions by the system planners and decision makers; it mainly depends upon three pillars given as:

1. Improve overall efficiency of existing electric system.

2. Maximize contributions (production \& use) of available types of renewable energies (RE).

3. Initiatel promote an impressive energy saving program and apply strategic plan for improve energy efficiency. 
Suggested points of solution are the main areas of implementation; they are already put in the pathway. Extra factors have also been included.

Actions have been taken for solution points $1 \& 2$ in power supply side have led to increase System overall efficiency to higher than 0.44 , increase availability of generating units up to $87 \%$, reduction in fuel consumption to $(0.209) \mathrm{gm}$ oil equivalent/KWH and reduction in System losses almost to $11 \%[6]$.

Point 3 of solution can be verified by bilateral cooperation between power provider and end users to achieve the goal of energy saving.

\section{ENERGY CONSERVATION AND IMPROVE ENERGY EFFICIENCY.}

Energy saving is defined as two terms energy conservation EC and energy efficiency improvement $\mathrm{EEl}$, first, energy conservation means less input power for lower output; for example air conditions and lighting with lower operating hours, switch off lights of unoccupied areas and stop unloaded motors ...Etc. Second, energy efficiency improvement means less input power for the same output; for example use high efficient electrical and electronic appliances and devices.

Factors influence applications of energy saving procedures are given in Fig (6).

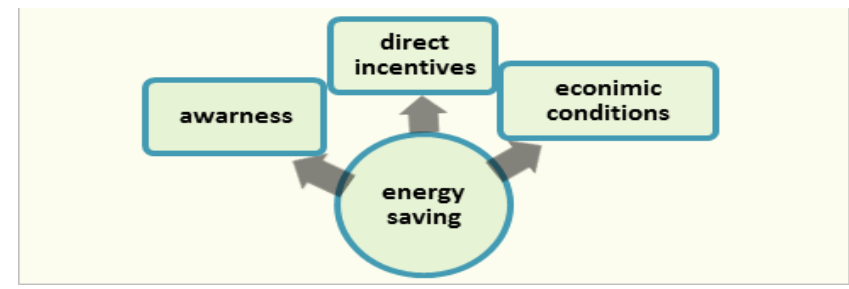

Fig .5. factors affect applications of energy saving techniques

Better use of electric energy is achieved by energy conservation, modifying efficiencies of equipment and customer behavior against use and consumption of energy as well.

\section{ENERGY SAVING FROM ECONOMIC AND ENVIRONMENTAL PERSPECTIVE}

Meeting the ever increasing in electric load demand coincides with high reliability and availability and in presence of a gap between oil and gas production; energy saving is a must.
Multiple advantages of energy savings are achieved for both power providers (electric utilities) and end users since energy saving is regarded as an additional source of power with low cost price for the reason that cost of saving energy is lower than cost of generating it.

\section{A. Benefits of Energy Saving for Electric System}

- Improve electric system overall efficiency.

- Reduce system losses and boost up voltage levels

- Perform better load profile \& lower peak demand

- Decrease fuel needed for electricity Production.

- Downsizing capacities of electrical generating units \& lengthen their expected life times.

- Declining energy costs especially at periods of peak demands.

- Reduce air pollutions and guarantee environmental safety.

\section{B. Benefits of Energy Saving for customer}

- Reduce customer electric energy bills.

- Increase customer system capacity for the same ratings of components.

- Possible extend in loads for the same contracted power.

- Lower losses and improved voltage drop.

- Higher customer system power quality.

\section{PROGRAMS OF ENERGY CONSERVATION IN EGYPT}

Several programs of energy Conservation have been conducted since mid1990`s up to date, Alexandria electricity distribution company (AEDC) has participated in several programs such as:

- Energy conservation and urban environment in Mediterranean countries (95-96), the program was sponsored by European commission, it has been planned to customer awareness of compact fluorescent lamps (CFL) and Primary studies in cogeneration techniques.

- USAID energy conservation and environmental project (DSM). The objectives were designed to, first develop and launch demand side management unit at AEDC. Second, test potential impacts of industrial DSM (96-97). 
- Energy and environmental auditing in small \& medium enterprises (SME'S) in Alexandria network, it intended to identify and evaluate opportunities for energy conservation and environmental protection for SME'S. Energy efficiency improvement \& green house gas reduction (EEIGGR) was sponsored by developing program of United Nations and in cooperation with (EEHC) Egypt's electricity holding company (992002).

- Energy conservation in governmental buildings in collaboration with (EEHC) and Alexandria governorate (2006-2007).

- Energy efficiency improvement for small industrial enterprises in cooperation with (IMC) industrial modernization center (2007-2010).

- Energy efficiency improvement in public lighting in collaboration with (EEHC) and ministries of industry \& trade, finance and social developments (2009).

- Energy conservation in worship houses mosques, cathedrals and churches in collaboration with (EEHC) (2010-2011).

- Energy efficiency improvement for small industrial enterprises in cooperation with (IMC) industrial modernization center (2015-2016).

\section{CASE STUDY}

In a program of energy conservation, a variety of medium scale end user utilities are selected to implement energy audit / survey to identify potentials of no cost/ low cost energy saving opportunities in administrative, commercial, industrial, worship houses and governmental facilities. Numbers of 50 utilities were included in the survey. Energy saving opportunities for electricity fuel and water were identified; reduction in emitted co2 was evaluated.

ost of investments and pay back periods for options were estimated.

High cost opportunities for energy savings are avoided and utility doesn't have the suitable demonstration project is excluded from the program.

\section{SEQUENCE OF PROGRAM EXECUTION}

Steps of completing the survey and reported the results are conducted according to the sequence given in Fig (6).

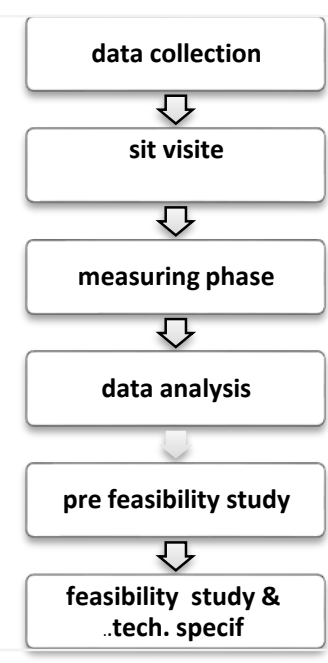

Fig .6. flow chart of energy saving reported program

\section{MEASURING PARAMETERS AND DEVICES}

Electrical measurements are executed by energy analyzer device at low voltage side of .a Customer plant. It is a robust device with ability to store an enormous amount of data in a memory box. Recorded data are transmitted to computers by interface unit and converted to graphs. Measuring parameters are volt (V), current (I), active \& reactive power (P\&Q), power factor (PF), harmonic total and individuals (THDV\%, V n\% THDI\%, I n \%). Measuring Period is a daylong or more to record variables during complete load cycle. Luxmeter is a device for measuring lighting intensity.

Thermal parameters are measured by gas analyzer device to measure exhaust (flue) gases as $02, \mathrm{co} 2$, \& co. Ultrasonic microphone to measure leakage in steam/ compressed air. Temperature sensor and barometer are also used.

\section{ENERGY SAVING PROGRAM DATA}

The program included 50 utilities represent groups of activities such as commercial buildings, hotels, cinema, conference centers, hospitals, worship houses, educational and governmental buildings, sports club,..Etc. Table (1) gives group No., activity types and \% weight of each. 

http://dx.doi.org/10.21622/RESD.2016.02.2.064

Table 1. activities types and numbers of categories

\begin{tabular}{|c|c|c|c|}
\hline $\begin{array}{c}\text { Group } \\
\text { No. }\end{array}$ & Activity type & Utilities no. & $\%$ weight \\
\hline 1 & Commercial building & 5 & 10 \\
\hline 2 & hotel & 6 & 12 \\
\hline 3 & Conference center & 2 & 4 \\
\hline 4 & Sport club & 1 & 2 \\
\hline 5 & hospital & 4 & 8 \\
\hline 6 & Resort \& tourist village & 3 & 6 \\
\hline 7 & Worship house & 2 & 4 \\
\hline 8 & Educational building & 1 & 2 \\
\hline 9 & Governmental building & 1 & 2 \\
\hline 10 & industrial facility & 25 & 50 \\
\hline & TOTAL & 50 & 100 \\
\hline
\end{tabular}

Several energy saving opportunities were achieved for facilities included in the survey. They are summarized as follows:

- Power factor improvement.

- Lighting system upgrade.

- Air condition \& heat ventilation system improvement.

- Boiler fuel consumption improvement.

- Steam distribution system efficiency improvement.

- Automatic control of steam feeding.

- Cogenerations \& waste heat recovery.

- Load management (demand control).

- Boiler blow down rate.

- Steam traps replacement and maintenances.

- Steam condensate system install \& maintenance.

- PV solar power and /or solar heating systems.

- Steam \& compressed air leakage minimize.

Results of survey show that most utilities use more than one type of energy source like electricity, fuel, steam and compressed air. Any utility almost has at least one opportunity for energy saving and improve lighting system is a common option for all individuals.

Many electrical, thermal and environmental options were achieved; they are classified as Reduction in power peak demand in megawatt (MW), saving in electrical energy consumptions in mega watt hour (MWH), fuel use reduction in tones and water use in cubic meter (m3) are evaluated. Corresponding reduction in energy cost in Pounds (LE) are estimated. Environmental impact due to saving in co2 in tones was computed. Cost of equipments in LE and pay back periods in years were calculated. Results are shown in tables (2) and (3).
Table 2. energy audits for 50 AEDC end user's sites \& energy savings

\begin{tabular}{|c|c|c|c|c|c|c|}
\hline \multirow{2}{*}{ Activity type } & \multirow{2}{*}{$\begin{array}{l}\text { Saving } \\
\text { options }\end{array}$} & \multicolumn{2}{|c|}{ saving } & \multirow{2}{*}{$\begin{array}{c}\text { Water } \\
(1000 \\
\text { m3) }\end{array}$} & \multirow{2}{*}{$\begin{array}{c}\text { Fuel } \\
\text { oil\#6 } \\
\text { (1000 } \\
\text { tone) }\end{array}$} & \multirow{2}{*}{$\begin{array}{c}\text { Penalti } \\
\text { es } \\
(1000 \mathrm{~L} \\
\quad)\end{array}$} \\
\hline & & MW & $\mathrm{MWH}$ & & & \\
\hline $\begin{array}{c}\text { Commercial } \\
\text { building }\end{array}$ & $\begin{array}{l}2,3 \\
\& 12\end{array}$ & 0 & 397.55 & 0 & 0 & 0 \\
\hline Hotels & $\begin{array}{l}1,2,3 \\
8 \& 9\end{array}$ & 0.312 & 1457.81 & 2.64 & 0.11 & 85.50 \\
\hline $\begin{array}{l}\text { Conference } \\
\text { center }\end{array}$ & $1 \& 2$ & 0 & 380.53 & 0 & 0 & 28.83 \\
\hline Sport club & $1 \& 2$ & 0 & 19.98 & 0 & 0 & 4.82 \\
\hline hospitals & $\begin{array}{l}1,2,5 \\
11 \& 13\end{array}$ & 0.342 & 1404.79 & 1 & 0.039 & 133.99 \\
\hline $\begin{array}{l}\text { Resort \& tourist } \\
\text { village }\end{array}$ & $1 \& 2$ & 0 & 688.96 & 0 & 0 & 9 \\
\hline Worship houses & $2 \& 3$ & 0 & 11.79 & 0 & 0 & 0 \\
\hline $\begin{array}{l}\text { Educational } \\
\text { building }\end{array}$ & 2 & 0 & 20.41 & 0 & 0 & 0 \\
\hline $\begin{array}{l}\text { Governmental } \\
\text { building }\end{array}$ & $2 \& 3$ & 0 & 63.11 & 0 & 0 & 0 \\
\hline $\begin{array}{l}\text { industrial } \\
\text { company }\end{array}$ & $\begin{array}{c}1,2,3 \\
4 \\
5,6,7 \\
89,10 \\
11 \\
12 \& 13\end{array}$ & 2.48 & 7527.88 & 249.02 & 235.37 & 708.38 \\
\hline \multicolumn{2}{|c|}{ Total saving } & 3.14 & 11972.8 & 252.67 & 235.52 & 970.52 \\
\hline
\end{tabular}

Table 3. results of energy saving $s$ and environment impact

\begin{tabular}{|c|c|c|c|c|}
\hline Activity type & $\begin{array}{c}\text { Saving co2 } \\
\text { (1000 tone) }\end{array}$ & $\begin{array}{c}\text { Total } \\
\text { saving } \\
\text { (1000L.E) }\end{array}$ & $\begin{array}{c}\text { Invested } \\
\text { Cost } \\
\text { (1000 L.E) }\end{array}$ & $\begin{array}{c}\text { Payback } \\
\text { period } \\
\text { (year) }\end{array}$ \\
\hline $\begin{array}{c}\text { Commercial } \\
\text { building }\end{array}$ & 0.34 & 95.97 & 132.08 & 1.38 \\
\hline Hotels & 1.43 & 364.73 & 448.25 & 1.23 \\
\hline $\begin{array}{c}\text { Conference } \\
\text { center }\end{array}$ & 0.29 & 98.65 & 144.95 & 2.8 \\
\hline $\begin{array}{c}\text { Sport club } \\
\text { Hospitals }\end{array}$ & 0.15 & 13.81 & 70.24 & 5.1 \\
\hline $\begin{array}{c}\text { Resorts \& tourist } \\
\text { villages }\end{array}$ & 0.52 & 128.70 & 74.54 & 0.58 \\
\hline $\begin{array}{c}\text { Worship houses } \\
\text { Gor }\end{array}$ & 0.01 & 1.80 & 5.19 & 6.6 \\
\hline $\begin{array}{c}\text { Educational } \\
\text { building }\end{array}$ & 0.014 & 3.67 & 4.15 & 1.1 \\
\hline $\begin{array}{c}\text { Governmental } \\
\text { building }\end{array}$ & 0.048 & 11.68 & 6.70 & 0.57 \\
\hline $\begin{array}{c}\text { Industrial } \\
\text { companies }\end{array}$ & 71.47 & 6008.33 & 6129.50 & 1.02 \\
\hline $\begin{array}{c}\text { TOTAL } \\
\text { Total }\end{array}$ & 74.94 & 7139.67 & 7469.92 & 1.05 \\
\hline
\end{tabular}


Calculations are based upon prices of all types of energies and costs of materials. Irrespective electricity tariff, prices of fuels and cost of materials are often unfixed; that don't change the ending results anyway. Calculations are performed based upon fuel consumption is 0.209 grams of oil equivalent per $\mathrm{KWH}$ and emission of warming gas co2 is $3.082 / \mathrm{kg}$ fuel.

Results obtained from a medium scale energy saving program implemented to 50 utilities represent different load categories such as commercial, educational, governmental buildings, hotels, sports clubs, conference centers, worship houses and industrial utilities evaluate and assess the benefits gained from energy conservation program applied to a random sample of loads.

Tables (1) \& (2) and (3) illustrate the results, it show that:

- Most savings are achieved in group (10) presented in table (1). It's weight\% is $50 \%$ but it provides savings between 0.63 to 0.99 of total savings, i.e. potentials of energy savings are considerable in industrial sector.

- Savings are remarkable in electrical energy consumption in groups $(4,7)$ despite cost of investments for each need relative long payback period.

- Total reduction is 3.14 M.W in peak load demand .Yearly Savings are 11972.8 MWH in electric energy, $252.67{ }^{*} 1000(\mathrm{~m} 3)$ in water and 235.52 *103 (tone) in fuel.

- Total cost saving is $7139.67^{*} 103$ L.E, estimated cost of investments is $7469.92^{*} 103$ L.E; overall payback period is 1.05 year.

- Good environment impact; reduction equals $74.94^{\star} 103$ tone of emitted gas co2 is accomplished

Investigation of results show that in any organization energy is often consumed somehow in an inefficient manner, excess consumptions in electricity, fuel and water are observed, therefore, energy conservation programs could be implemented upon any class of business. Results are significant. Procedures of improvements are almost simple and easily Applied, Invested cost isn`t highly sound, payback periods are very limited and positive effect upon environment is extremely attained.

\section{CONCLUSIONS}

Since Egypt's electric system encounters several challenges that seriously affect its performance from view points of continuity, adequacy and quality that may reflect negatively upon satisfaction of consumers and detrimentally have an effect on economic situation; this has push decision makers and system planners to establish a strategic plan for solution depends on three supports including; efficiency improvement of present electric system, scale up contributions and use of all available types of renewable energies and promote/encourage energy saving programs, adding to installation of coal fired electric power plants and nuclear power stations.

Shortage in natural resources of prime energies oil \& natural gas, volatile in petroleum prices in world markets and guarantee safety of environment as a result of fossil fuel fired power plants make the challenges are great. Although increase contribution of renewable energies in Egypt's electric system is suitable solution in long run, it also controlled by extremely large invested cost needed by local or foreign financiers. As will as setting up power plants certainly require few years till electricity begins to generate.

Energy saving seems to be the key factor for assurance of adequacy, continuity and quality of power supply. Electric utilities especially distribution companies are in the heart of events, they have a big role in involving the end users participation in energy saving programs, the customer 's awareness, guidance and support will lead to wonderful results. Media and social organizations have also a great responsibility in drive the individuals towards energy savings.

\section{REFRANCES}

[1] "Future Options for Energy Production and Consumption in Egypt, International Policy Published El Ahram Magazine - Egypt, 2014.

[2] "Oil Peak Production, Research by Dr. Mahmud Refaee, Published Oil Peak in Arabic.Org, www. The gulf biz.com/vb/forum.php 2009,

[3] "Renewable Energy And Energy Efficiency Open The Pathway To Affordable Sustainable Energy,, Dr. Paul H. Suding, International Green Renewable Energy Conference (IGREC), Cairo 2009. 
[4] "Renewable Energy Strategy for 2020 and Regulatory Frame Work, Dr. Hafez Salmawii, Electric Regulatory and Customer Protection Agency magazine - Egypt, 2009.

[5] "Fossil Fuel Energy Consumption and depletion, Dr. Mohamed Zohiary, published in petroleum \& energy conference, Mansura University 2008.

[6] Egypt regulatory Electricity Agency and customer protection (Egypt era) periodic magazine 2015

[7] "75 Potentials of Energy Savings in industrial and commercial installations, Hand Book, Dr. Camellia Yusuf, Egypt, 2003.
[8] "Energy Conservation Opportunities in Electric Distribution System, Hand Book, Dr. Camellia Yusuf, Egypt, 2002.

[9] "Demand Side Management,, manual published by energy conservation \& environment project, sponsored by USAID, 1995.

[10] http:// www.iea.org/statist/index.htm.

[11] https://www.openoil.net/wiki/ar/index.php. 